\title{
A Metaphoric Study of Chinese Sun Myths
}

\author{
Hao Dong \\ Foreign Languages Department \\ AFAU \\ Changchun Jilin Province, China \\ syhawk@sina.com
}

\begin{abstract}
This paper is a cognitive metaphoric study of Chinese Sun myths. Analysis of related myths reveals that in Chinese Sun myths descriptions of Sun are full of metaphors, and all these metaphors are based on bodily experiences of primeval human beings.
\end{abstract}

Keywords-sun; myth; metaphorical; analysis

\section{INTRODUCTION}

Myth is defined as "a traditional, typically ancient story dealing with supernatural beings, ancestors, or heroes that serves as a fundamental type in the world view of a people, as by explaining aspects of the natural world or delineating the psychology, customs, or ideals of society" (American Heritage Dictionary). It reveals the philosophy and history of the primeval human beings.

Lakoff \& Johnson argue that human thought processes are largely metaphorical and the human conceptual system is metaphorically structured and defined. Metaphors as linguistic expressions are possible precisely because there are metaphors in a person's conceptual system. (1980) Researches on cognitive linguistics show that human minds are embodied, and thinking and reasoning are largely metaphorical and imaginative, shaped by the human body (Gibbs 1994; Johnson 1987; Lakoff 1987; Lakoff \& Johnson 1980, 1999; Schmitt, 2000). Now that human understanding of the world is metaphorical, myth, as the way to understand the world by primeval human beings, must also be metaphorical. Myths are viewed as a whole set of metaphors, an underlying art of metaphor, and every object within it implies other things. (Zhu, 1999) Midgley (2003) also claims that myths are imaginative patterns, networks of powerful symbols that suggest particular ways of interpreting the world. They relate to metaphors, for "metaphorical concepts ... are living parts of powerful myths". She proclaims that "such symbolism is an integral part of our thought-structure ...merely a surface dressing of isolated metaphors" This basic insight that myths affect our interpretation of the world - and particularly our science flavors the entire volume, which focuses on the myths of individualism, inter-related human nature / subject-object / mind-body / reason-feeling dualities, omnicompetent science, progress and the social contract.

Sun myth is a very important part of myths of every nation. With analysis of Chinese Sun myth, this article tends to find the underlying omnipresent metaphorical ground.

\section{CHINESE SUN MYTHS}

Sun myth present themselves in nearly all nations and all areas, for Sun plays radical roles in human life. The system of Sun myth, in light of the significances of Sun in human existence, mainly consists of birth of Sun, sex of Sun, rotation of Sun, and calamity of Sun.

According to Chinese ancient records, a lady called Xihe gave birth to ten Suns. They were all male. They by turns did the duty. One Sun set out from the east in the morning and traveled in the sky toward the west for a whole day. When he was coming near the west, the night was coming. The one on duty drove a splendid vehicle, and spread brilliant rays of light. Occasionally Heaven Dog attacked Sun, and there appeared an eclipse. Once ten Suns came out and traveled in the sky together which brought about severe drought. A hero named Yi shot down nine Suns out of ten, and universal orders were restored. Since then, human beings have only one Sun in the sky. (Mao, 1981; Yuan, 1979; Ye, 1992)

\section{ANALYSIS OF CHINESE SUN MYTHS}

Levy-Bruhl, French philosopher and anthropologist, proposed the concept of "original logic thinking". He points out that primeval human beings are very poor at abstract thinking, but they are adept at visual thinking and analogy. They visualize the world and myths are their intellectual products. Pure external phenomena are inexistent, and there are no clear distinction between human and the outside world or between an individual and other people. (Chen, 2001)

When explaining those phenomena about Sun, primeval human beings completely analogize by making use of their own bodily experiences, namely, they see Sun as human existence as themselves, but with superhuman mightiness.

Sun was born into the world, instead of coming into being without foundation, for every human being is born into the world. Sun had sex, for every human being is male or female. Suns have brothers, for human beings have companions. Sun traveled everyday, just as human beings move here to there to seek food. Sun traveled along the same route, just as human beings live and die in the eternal cycle, namely, samsara. Eclipses were symptoms of injuries, for human all fall sick from time to time. Nine Suns were shot dead, for human beings are also in danger of being killed, especially for primeval human beings. But Sun is never an ordinary human being. He emits rays and heat, which are the source of life on Earth. His 
travel indicates the alternation of day and night. Thus Sun is called "taiyang [great Sun]" in Chinese.

Based on mentioned facts, we are able to judge that metaphors from human life to Sun are systematic, and the metaphorical projection goes as the following:

$\begin{array}{ccc}\text { Source Domain } & & \text { Target Domian } \\ \text { Human life } & \rightarrow & \text { Sun } \\ \text { Birth } & \rightarrow & \text { Beginning of existence } \\ \text { Travel } & \rightarrow & \text { Move from east to west } \\ \text { Samsara } & \rightarrow & \text { Rotation } \\ \text { Being injured } & \rightarrow & \text { Eclipse } \\ \text { Death } & \rightarrow & \text { End of existence }\end{array}$

The primeval human beings use bodily experience to explain all phenomena about Sun. We can see it in myths handed down to present days. However, people use these metaphors all the same nowadays, namely, there is still metaphoric relations between Sun and human life. The metaphorical projection goes as the following:

Here are a few examples that manifest the metaphorical relations.

$\begin{array}{ccc}\text { Source Domain } & & \text { Target Domain } \\ \text { Sun } & \rightarrow & \text { Human life } \\ \text { Sunrise } & \rightarrow & \text { Birth } \\ \text { Being male } & \rightarrow & \text { Manliness } \\ \text { Daily traveling } & \rightarrow & \text { Daily routines } \\ \text { Rotation } & \rightarrow & \text { Samsara } \\ \text { Sunset } & \rightarrow & \text { Death }\end{array}$

A. Nimen Shi Zaoshang Bajiu Dian Zhong De Taiyang. [you are morning eight nine point clock SUB Sun ] 'You're the rising sun at about eight or nine o'clock.'

\section{B. Ri Bo Xishan}

[Sun near west mountain]

'near one's death'

\section{Sheng Ri. \\ [birth Sun] \\ 'birthday'}

\section{Yang Gang}

[sun strong]

'manly'

\section{E. Yang Wei}

[Sun wither]

'impotence'

F. Rizi

[Sun ZI]

'day'

\section{G. Ri Fu Yi Ri}

[Sun repeat one Sun]

'day after day'

\section{H. Yangjian}

[Sun space]

'the world'

Example A, B and $\mathrm{C}$ show that the birth and death are compared to the rise and fall of Sun. Example D and E exemplify that the male Sun is used to manifest the manliness of man. Example F and $\mathrm{G}$ denote that the repetition of Sun's daily travel is used to stand for the period of one day. Example $\mathrm{H}$ highlights the relationship between Sun and human beings.

\section{CONCLUSION}

In ancient Sun myths, Sun is viewed as a male human being. With the above discussion, we are safe to say that there are systematic metaphors between Sun and human beings. The myths explaining the existence of Sun make use of human experiences, and Sun phenomena are also used to express human experiences.

\section{ACKNOWLEDGMENT}

I need to give my thanks to my sister and my mother. They give me unselfish help whenever I ask for help. Thanks to my dear friend Haomiao, without her, I can not get the inspiration and finish this paper.

\section{REFERENCES}

[1] Gibbs, R. W. (1994). The poetics of mind: Figurative thought, language, and understanding. New York: Cambridge University Press, pp. 38-49.

[2] Johnson, M. (1987). The body in the mind: The bodily basis of meaning, imagination, and reason. Chicago: University of Chicago Press, pp. 122156. 
[3] Lakoff, G. (1987). Women, fire and dangerous things: What categories reveal about the mind. Chicago: The University of Chicago Press, pp. 86-97,

[4] Lakoff, G., \& Johnson, M. (1980). Metaphors we live by. Chicago: The University of Chicago Press, pp. 23-56.

[5] Lakoff, G., \& Johnson, M. (1999). Philosophy in the flesh: The embodied mind and its challenge to western thought. New York: Basic Books, pp.69-90, 154-168.
[6] Midgley, M. (2003). The myths we live by. London/New York: Routledge, pp.58-64.

[7] Schmitt, R. (2000). Notes towards the analysis of metaphor. Forum: Qualitative Social Research [On-line Journal], 1(1). http://qualitativeresearch.net/fqs. 